\title{
Investigation on Various Aboveground Traits to Identify Drought Tolerance in Cowpea Seedlings
}

\author{
Waltram Ravelombola and Ainong Shi ${ }^{1}$ \\ Department of Horticulture, University of Arkansas, Fayetteville, AR 72701
}

\section{Jun Qin}

National Soybean Improvement Center Shijiazhuang Sub-Center, North China Key Laboratory of Biology and Genetic Improvement of Soybean Ministry of Agriculture, Cereal \& Oil Crop Institute, Hebei Academy of Agricultural and Forestry Sciences, Shijiazhuang, Hebei 050031, China; and Department of Horticulture, University of Arkansas, Fayetteville, AR 72701

Yuejin Weng, Gehendra Bhattarai, Bazgha Zia, and Wei Zhou

Department of Horticulture, University of Arkansas, Fayetteville, AR 72701

\section{Beiquan Mou}

Crop Improvement and Protection Research Unit, U.S. Department of Agriculture, Agricultural Research Service (USDA-ARS), 1636 E. Alisal Street, Salinas, CA 93905

Additional index words. cowpea, germplasm, evaluation, drought, seedling, Vigna unguiculata

Abstract. Impacts of drought stress on crop production can sionificantly impair farmer's revenue, hence adversely impacting the gross national product growth. For cowpea [Vigna unguiculata (L.) Walp.], which is a legume of economic importance, effects of drought at early vegetative growth could lead to substantial yield losses. However, little has been done with respect to breeding for cowpea cultivars withstanding drought at early vegetative growth. In addition, previous investigations have focused on how plant morphology and root architecture can confer drought tolerance in cowpea, which is not sufficient in efforts to unravel unknown drought tolerance-related genetic mechanisms, potentially of great importance in breeding, and not pertaining to either plant morphology or root architecture. Therefore, the objective of this study was to evaluate aboveground drought-related traits of cowpea genotypes at seedling stage. A total of 30 cowpea genotypes were greenhouse grown within boxes and the experimental design was completely randomized with three replicates. Drought stress was imposed for 28 days. Data on a total of 17 aboveground-related traits were collected. Results showed the following: 1) a large variation in these traits was found among the genotypes; 2) more trifoliate wilt/chlorosis tolerance but more unifoliate wilt/chlorosis susceptible were observed; 3) delayed senescence was related to the ability of maintaining a balanced chlorophyll content in both unifoliate and trifoliate leaves; and 4) the genotypes PI293469, PI349674, and PI293568 were found to be slow wilting and drought tolerant. These results could contribute to advancing breeding programs for drought tolerance in cowpea.

Drought stress has been constraining agricultural production in various ways, which increasingly threatens food availability globally. Drought has been described as the effects of a sustained lack of soil moisture required for plants to properly grow and provide sufficient crop yields (Blum and Ebercon, 1981). A long period of drought conditions adversely affects plant growth development, and extreme cases result in plant death (Golldack et al., 2014). As a result, drought stress can significantly impair the economy (Ishiyaku and Aliyu, 2013). In the United States, Rosine and Bull (1989) reported that crop losses due to drought stress unfavorably affected the gross national product growth.

Received for publication 7 June 2018. Accepted for publication 15 Oct. 2018.

${ }^{1}$ Corresponding author. E-mail: ashi@uark.edu.
The U.S. National Drought Center at the University of Nebraska stated that little has been done to help farmers become well prepared with drought stress (Wu and Wilhite, 2004). Cultivars that can tolerate limited water supplies at early vegetative growth could be an affordable solution to overcome drought conditions. Reports showed that impacts of drought on crops such as cowpea have been acute in tropical and subtropical regions (Carvalho et al., 2017).

Cowpea [Vigna unguiculata (L.) Walp.], $2 n=2 x=22$, is one the most economically important legumes widely grown in subSaharan Africa (Singh et al., 2003). Cowpea is a good source of protein for human consumption (Weng et al., 2017). Cowpea provides micronutrients, such as iron and zinc, which are essential to the diet of humans (Frota et al., 2008). Cowpea is also a health-promoting food due to the significant amount of antioxidants found in cowpea seeds (Moreira-Araújo et al., 2017). In addition to being part of the diet of humans, cowpea is also used as feed for livestock.

Cowpea is one of the most droughttolerant legumes (Agbicodo et al., 2009); however, drought conditions occurring at early season could be detrimental to cowpea production (Muchero et al., 2009). Significant industry dealing with cowpea cultivation has been noticed in the southern and western parts of the United States, because cowpea is an economically profitable crop to grow (Okiror et al., 2008). Evidence of drought conditions has been reported in these areas (Escalante et al., 2016), which could limit cowpea production; however, little has been done toward advancing breeding programs for drought tolerance in cowpea compared with other legumes (Specht et al., 2001).

Because drought tolerance consists of complex mechanisms, identifying traits for reliably assessing drought tolerance could be challenging in cowpea (Verbree et al., 2015). Providing growers with crops that better withstand drought conditions requires effective and strong breeding programs through the establishment of a better phenotyping and screening approach. Fatokun et al. (2012) conducted a field experiment to evaluate drought tolerance in cowpea; however, possible heterogeneity due to uncontrolled factors, such as temperature and water transmission within soils, could significantly affect field results.

The seedling stage is one of the most sensitive stages to drought stress in cowpea (Agbicodo et al., 2009). Phenotyping drought tolerance at the seedling stage in a controlled condition could contribute toward advancing breeding programs for drought tolerance in cowpea. In addition, little has been done regarding screening drought tolerance in cowpea by limiting adaptation due to plant morphology and root architecture, which can contribute to finding unexplored genetic mechanisms underlying drought tolerance. To date, cowpea cultivars that have been proven to be drought tolerant at the seedling stage remain limited. Exploring a new source of variation of drought tolerance is essential for sustainably enhancing resilience to water 
deficit conditions in cowpea. This could be achieved by investigating various drought tolerance-related traits. Responses of aboveground plant parts to drought stress occurring at the seedling stage have been less studied in cowpea, although they can provide substantial information on key drought-tolerance mechanisms. In addition, understanding how the different drought tolerance-related traits are related to each other could help in elucidating the complex mechanism pathways conferring drought tolerance in cowpea. Therefore, the objective of this study was to assess the effects of drought on aboveground traits in cowpea, and to identify drought-tolerant cowpea genotypes based on those traits at the seedling stage.

\section{Materials and Methods}

\section{Plant materials}

A total of 30 cowpea genotypes were used in this study, and they originated from 14 countries (Australia, Botswana, Brazil, Ghana, India, Iran, Kenya, Mexico, Nigeria, Paraguay, Saudi Arabia, Tanzania, Trinidad and Tobago, and the United States) (Table 1). Of the 30 cowpea genotypes, 3 were advanced breeding lines developed by the University of Arkansas, Fayetteville, AR. The remaining were PIs from the U.S. Department of Agriculture (USDA) Germplasm Resources Information Network (GRIN) cowpea accessions, which was provided by the USDA Plant Genetic Resources Conservation Unit at Griffin, GA. Seeds were increased at the Arkansas Agricultural Experiment Station of the University of Arkansas, during the Summer 2016. After harvest, seeds were cleaned, and those with uniform size and that were free of disease and insect damage were used for the experiments.

\section{Growth conditions and drought stress}

Evaluation of drought tolerance was conducted in the greenhouse of Harry R. Rosen Alternative Pest Control of the University of Arkansas. Greenhouse day/night temperatures were maintained at $26^{\circ} \mathrm{C} / 21{ }^{\circ} \mathrm{C}$, and daylight length was $14 \mathrm{~h}$ (Fig. 1). Screening methodology was similar to that adopted by Singh et al. (1999) and Verbree et al. (2015) with slight modifications. Cowpea planting was conducted in the Sterilite polypropylene boxes (Sterilite Corporation, Townsend, MA) with dimensions $88.6 \times 42.2 \times 15.6 \mathrm{~cm}$, previously filled with Sunshine ${ }^{\circledR}$ Mix \#1 Natural \& Organic (Sun Gro Horticulture, Agawan, MA) up to $10.5 \mathrm{~cm}$ high. Two days before planting, each box was irrigated with $12 \mathrm{~L}$ of tap water so that field capacity was attained at sowing time.

Within each box, a total of ten $7.5-\mathrm{cm}-$ spaced rows were designed across the box length. Each cowpea genotype was planted within each row. A total of six uniform and vigor plants were kept at each row when the first trifoliate leaf began to expand. One week after plant emergence from soil medium, Miracle-Gro fertilizers (Scotts Miracle-Gro, Detroit, MI) were applied. Each row was irrigated with $150 \mathrm{~mL}$ of tap water every $3 \mathrm{~d}$ until the first trifoliate leaf was fully developed. Drought stress was imposed by stopping water irrigation when the first trifoliate was completely expanded, and pursued until some genotypes were completely dead, indicating susceptibility to drought stress. Soil moisture measure within boxes was recorded using an HH2 Moisture Meter (Delta-T Devices, Cambridge, UK) every $3 \mathrm{~d}$.

The experiment was conducted using a completely randomized design with three replicates per genotype and six plants in each replicate. Treatments were the 30 cowpea genotypes for evaluation of drought tolerance. The treatment was assumed to have a fixed effect. The experimental unit was each row where genotypes were planted as fixed effect as well in the study.

\section{Measurements}

Aboveground-related traits. Traits involving plant greenness, stem diameter, lodged plants, wilted plants, plants exhibiting necrotic stems, plants showing dead growing points, percentage of dead plants, and recovery rate after rewatering were recorded. Plant greenness was assessed using a 1 to 5 scale $(1=$ plants were completely green, $2=$ plants began losing greenness, $3=$ signs of chlorosis and necrosis were visible, $4=$ chlorosis and necrosis was severe, and $5=$ plants were completely dead) (Fig. 2). Data on plant greenness was recorded on a per plant basis in 4 weeks after first imposing drought stress. At that time, some genotypes were completely dead (Fig. 3). If the average plant greenness scores were lower than the population average at 4 weeks of drought stress, the accession was considered slow wilting; otherwise, it was considered fast wilting (Fig. 3).

When the first signs of wilting appeared, stem diameter was recorded at $1 \mathrm{~cm}$ above the soil medium using a digital caliper. Data on

Table 1. Cowpea accessions (30 genotypes) used for drought tolerance evaluation at seedling stage.

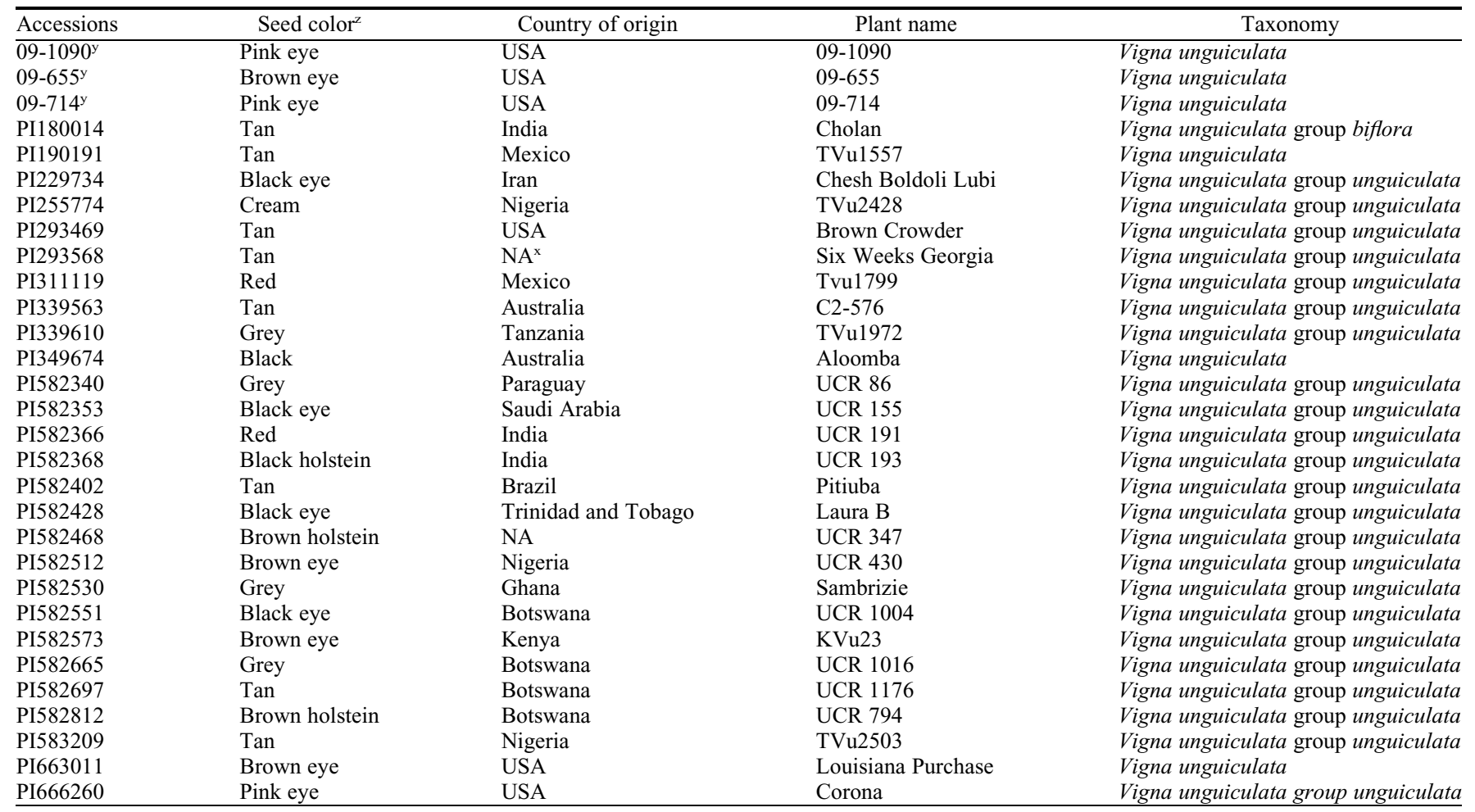

${ }^{\mathrm{z}}$ Seed color was established using the cowpea seed color classification found at https://npgsweb.ars-grin.gov/gringlobal/descriptors.aspx?

${ }^{\mathrm{y}}$ Advanced breeding lines developed by the University of Arkansas, Fayetteville.

${ }^{\mathrm{x}}$ Information was not available (NA). 
(A)

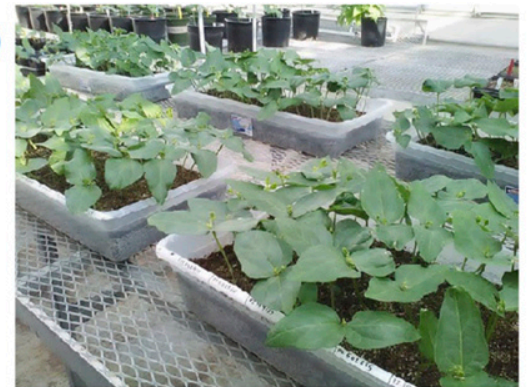

(B)

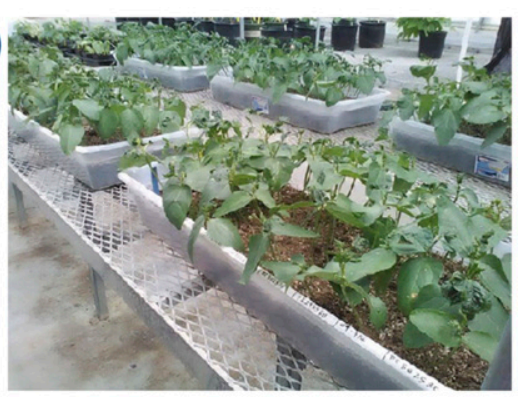

(C)

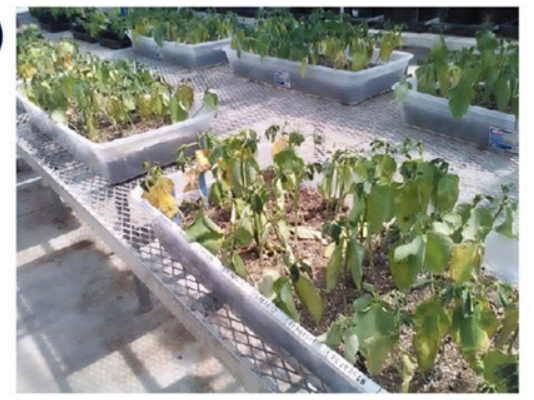

(D)

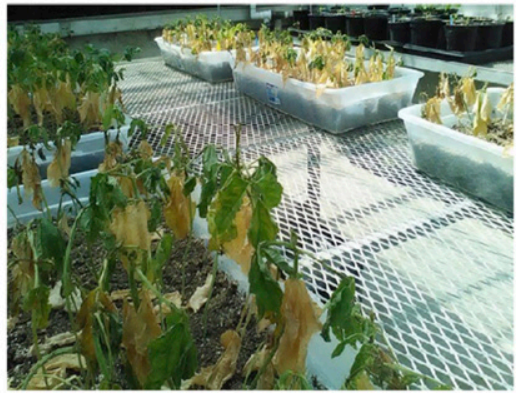

Fig. 1. Greenhouse phenotyping experiments for drought tolerance at seedling stage in cowpea: (A) drought stress was imposed for $7 \mathrm{~d}$, (B) for $14 \mathrm{~d},(\mathbf{C})$ for $21 \mathrm{~d}$, and (D) for $28 \mathrm{~d}$ (Photo: Dr. Ainong Shi).

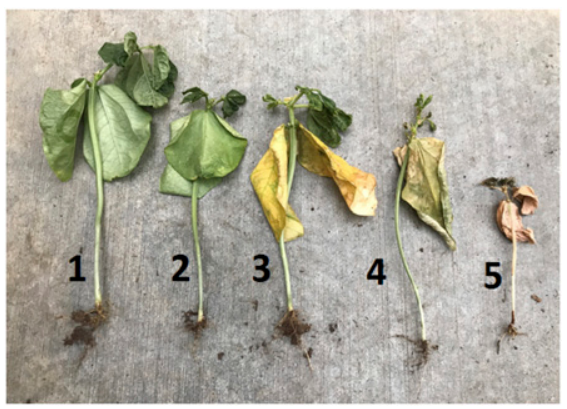

Fig. 2. Overall plant greenness assessed on a 1 to 5 scale: 1 = plants were completely green, $2=$ plants began losing greenness, $3=$ signs of chlorosis and necrosis were visible, $4=$ chlorosis and necrosis was severe, and $5=$ plants were completely dead (Photo: Dr. Ainong Shi).

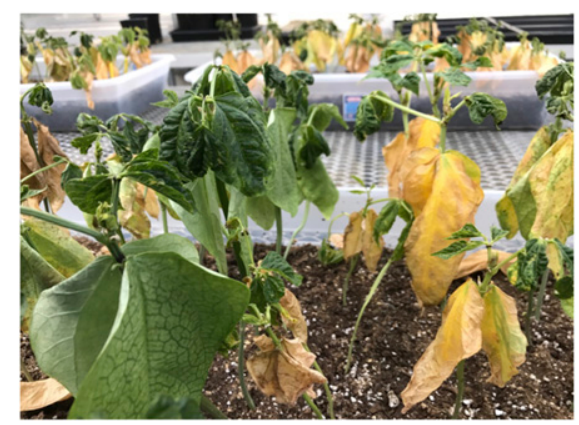

Fig. 3. Slow-wilting (green) and fast-wilting (yellow) cowpea genotypes at $28 \mathrm{~d}$ of drought stress (Photo: Dr. Ainong Shi).

percentage of dead plants, lodged plants, wilted plants, plants exhibiting necrotic stems, and plants showing dead growing points were collected on a per row basis at 4 weeks after the last watering. Recovery rate after rewatering for each genotype was evaluated on per row basis as well.

Leaf-related parameters. Leaf-related traits have been used to identify drought tolerance in cowpea (Verbree et al., 2015). Unifoliate leaf length and width were measured before drought stressing the cowpea plants. When some genotypes were completely dead whereas others remained green, the number of plants showing unifoliate leaf wilt and chlorosis and trifoliate wilt and chlorosis were counted on a per row basis.

In vivo chlorophyll measurement. Chlorophyll was measured using SPAD-502 Plus (Spectrum Technologies, Inc., Plainfield, IL). Chlorophyll on trifoliate leaves and unifoliate leaves was measured separately because tolerance to trifoliate leaf wilting/chlorosis and unifoliate leaf wilting/chlorosis are two different mechanisms of drought tolerance in cowpea, as described by Verbree et al. (2015). Measurements were conducted weekly after drought stress was applied. Data on chlorophyll content were taken from all plants. On each leaf, measurements were done three times at different positions to avoid edge effect. The average among the three measurements was recorded. In addition, the ratio between the chlorophyll contents from trifoliate leaves and unifoliate leaves, respectively, was calculated.

\section{Data analysis}

Analysis of variance (ANOVA) was performed using PROC MIXED of SAS ${ }^{\circledR} 9.4$ (SAS Institute, Inc., Cary, NC). Mean separation was done using a protected least significant difference procedure (protected least significant difference) at $\alpha=0.05$ in $\mathrm{SAS}^{\circledR}$ 9.4. Analysis of chlorophyll content was achieved through ANOVA using time as a repeated measure because observations over time were from the same experimental unit, thus could not be assumed independent. ANOVA involving time series required the identification of the appropriate covariance matrix before the analysis (Littell et al., 2000). Covariance matrix used for ANOVA with repeated measures was that of corresponding to the lowest Bias-Corrected Small Sample Akaike Information Criterion (AICC) as described by Littell et al. (2000).

Types of covariance structure from which the selection was done were unstructured, independence with equal variance, first order autoregressive, Toeplitz, Toeplitz with two bands, Toeplitz with three bands, heterogeneous independence, and heterogeneous first autoregressive (Littell et al., 2000). The values of AICC for each covariance structure were calculated through $\mathrm{SAS}^{\circledR}$ 9.4 using the options "type=un," "type=vc," "type=ar(1)," "type=toep," "type=toep(2)," "type=toep(3)," "type=un(1)," and "type= $\operatorname{arh}(1), "$ respectively.

The statistical model for ANOVA with repeated measures for a completely randomized design was the following:

$\mathrm{Y}_{\mathrm{ijk}}=\mu+\mathrm{G}_{\mathrm{i}}+\mathrm{y}_{\mathrm{k}(\mathrm{i})}+\mathrm{D}_{\mathrm{j}}+\mathrm{GD}_{\mathrm{ij}}+\varepsilon_{\mathrm{ijk}}$,

where $Y_{i j k}$ represented the chlorophyll content of the $i^{\text {th }}$ genotype $(i=1,2, \ldots, 30)$ at the $j^{\text {th }}$ week $(j=1,2,3)$ of drought stress and on the $k^{\text {th }}$ replicates $(\mathrm{k}=1,2,3), \mu$ was the overall mean, $G_{i}$ was the effect of the $i^{\text {th }}$ genotype (fixed effect) on the mean response, $\eta \eta_{k(i)}$ was independent error terms associated with the genotypes where $\eta_{k(i)} \sim N\left(0, \sigma^{2}\right), D_{j}$ was the effect of $j^{\text {th }}$ week on the mean response, $G_{i j}$ denoted the interaction effect between the $i^{\text {th }}$ genotype and the $j^{\text {th }}$ week on the mean response, and $\varepsilon_{\mathrm{ijk}}$ was the error term associated with the interaction effect whose covariance matrix structure depended on the AICC value.

Pearson's correlation coefficients between trait values were calculated using JMP Genomics ${ }^{\circledR} 7$ (SAS Institute, Inc.). Descriptive statistics were generated using the "Tabulate" options of JMP Genomics ${ }^{\circledR} 7$ (SAS Institute, Inc.). Combined violin and boxplots were drawn using the packages "ggplot2," "labeling," and "gridExtra" of R 3.3.0. Network path analysis between traits evaluated for drought tolerance and heatmap for chlorophyll content were drawn using the packages "network" and "gplots," respectively, of R 3.3.0 as well.

\section{Results}

\section{Soil moisture content}

Soil moisture content within the Sterilite polypropylene boxes where cowpea was grown significantly dropped from an average of $55 \%$ to $22 \%$ at $7 \mathrm{~d}$ of drought stress (Fig. 4). At $14 \mathrm{~d}$, average soil moisture content was close to $10 \%$, and in that time, the plant wilting was observed. The decreasing moisture in soil triggered drought stress in cowpea plants. The sustained insufficiency in soil moisture over time (Fig. 4) induced severe drought conditions, which is critical for drought tolerance evaluation in cowpea at the seedling stage. Some cowpea genotypes were not able to withstand a long period of drought conditions, as shown in Fig. 1. 


\section{Aboveground-related traits}

Some cowpea genotypes were completely dead at $28 \mathrm{~d}$ after drought stress. Plant greenness score at $28 \mathrm{~d}$ after drought stress varied from 1.42 to 4.47 , with an average of 3.69 and an SD of 0.58 (Supplemental Table 1). A significant variation in plant greenness score was identified among the 30 cowpea genotypes evaluated for tolerance to drought stress $(F=7.31, P<0.0001)$ (Table 2). Mean separation analysis revealed data PI293469 (1.42), PI349674 (2.83), and PI293568 (2.89) (Supplemental Table 1) had the lowest overall plant greenness score, indicating significant delayed senescence to cope with drought condition in those genotypes, thus tolerant to drought stress based on plant greenness score. PI582573 (4.47), PI582665 (4.33), PI229734 (4.33), PI255774 (4.33), PI666260 (4.28), and PI666260 (4.13) (Supplemental Table 1) had the highest overall plant greenhouse score, suggesting that these genotypes failed to delay leaf senescence under drought stress, hence these genotypes were drought-susceptible based on plant greenness score. Because the population mean for plant greenness score was 3.69, for this experiment, those having a plant greenness score lower than the population mean was considered slow wilting; otherwise, they were fast wilting. Slow-wilting genotypes were 09-1090, 09-655, PI293469, PI293568, PI311119, PI582340, PI582366, PI582402, PI582551, PI582697, and PI583209 (Supplemental Table 1).

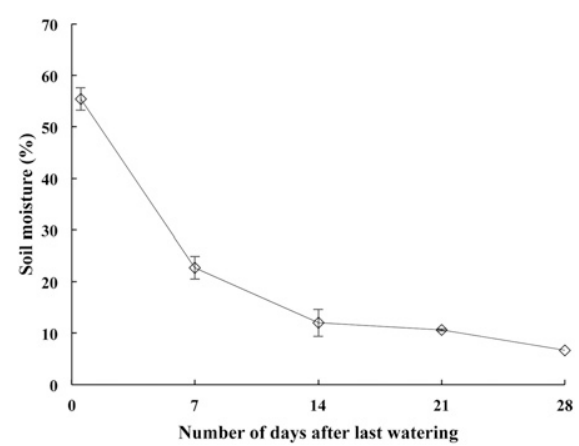

Fig. 4. Soil moisture content over time during drought stress.
Stem diameter was recorded at first sign of plant wilting. Stem diameter was in the range of $2.45 \mathrm{~mm}$ to $3.69 \mathrm{~mm}$, with an average of $2.96 \mathrm{~mm}$ and an SD of $0.28 \mathrm{~mm}$. ANOVA revealed a statistically significant difference in stem diameter among the cowpea genotypes $(F=3.52, P<0.0001)$ (Table 2). The genotypes having the largest stem diameter at the first sign of wilting were PI293469 (3.69 mm), PI582402 $(3.62 \mathrm{~mm})$, and 09-714 $(3.48 \mathrm{~mm})$, whereas those having the shortest stem diameter were PI180014 (2.69 mm), PI582366 (2.67 mm), PI582573 (2.67 mm), PI339563 (2.66 mm), PI582512 (2.62 mm), and PI582812 (2.45 mm) (Supplemental Table 1).

The percentage of dead plants per genotype was recorded at $28 \mathrm{~d}$ after drought stress. At that time, some genotypes were completely dead. The percentage of dead plants per genotype varied from $0 \%$ to $100 \%$, with an average of $54.26 \%$ and an SD of $25.98 \%$. Statistical analysis showed that the significant differences were observed in percentage of dead plants among the cowpea genotypes $(F=29.86, P<0.0001)$ (Table 2$)$. The genotypes having the lowest percentage of dead plants were PI293469 (0), PI293568 (8.33\%), PI349674 (8.44\%), and PI582402 $(9.70 \%)$, indicating that the four genotypes were drought tolerant, whereas accessions showing the highest percentage of dead plants were PI582665 (91.67\%), PI255774 (91.67\%), PI582573 (93.89\%), PI229734 (97.22\%), and PI666260 (100\%) (Supplemental Table 1). Slow-wilting genotypes had a percentage of dead plants lower than $50 \%$ on average, whereas that of fast-wilting genotypes was greater than $50 \%$ (Fig. 5B).

A large variation in percentage of lodged plants was found among the cowpea genotypes. Percentage of lodged plants varied from $0 \%$ to $100 \%$, with an average of $44.28 \%$ and an SD of $26.74 \%$. The percentage of lodged plants was statistically significantly different among the genotypes $(F=21.06$, $P<0.0001$ ) (Table 2). On average, fewer than $10 \%$ of plants were lodging under drought stress for the genotypes PI582340 (0), PI293469 (0), PI339610 (8.33\%), PI293568 (8.33\%), and PI349674 $(9.11 \%)$, whereas percentage of lodged plants was greater than $90 \%$ for the genotypes PI229734 (92.22\%), PI582573
(93.56\%), and PI666260 (100\%) (Supplemental Table 1), suggesting that these genotypes were highly susceptible to drought stress. Percentage of lodged plants in the fastwilting genotypes was higher than in the slow-wilting genotypes (Fig. 2D).

Most of the cowpea genotypes presented wilting signs under severe drought conditions (Supplemental Table 1) (Fig. 1). ANOVA revealed significant difference in percentage of wilted plants among the cowpea genotypes evaluated from drought tolerance at seedling stage $(F=20.57, P<0.0001)$ (Table 2$)$.

Significant differences in proportion of plants with necrotic stems were identified $(F=15.17, P<0.0001)$ (Table 2$)$. The percentage of plants showing necrotic stems ranged from $8.33 \%$ to $100 \%$, with an average of $55.37 \%$, and an SD of $27.32 \%$. Few plants were affected by stem necrosis for the genotypes PI293469 (8.33\%), PI349674 (10.17\%), and PI293568 (16.67\%), indicating that the four genotypes were tolerant to stem necrosis under drought conditions. The genotypes PI339563 (86.90\%), PI582812 (87.50\%), PI582573 (87.78\%), PI582468 (90\%), PI339610 (91.67\%), and PI229734 (100\%) were highly susceptible to stem necrosis under drought stress (Supplemental Table 1). Both distributions and average percentage of plants with necrotic stem were different between fast-wilting and slow-wilting genotypes (Fig. 5B).

The percentage of plants with dead growing points was in the range of 0 and $100 \%$, with an average of $56.76 \%$ and an SD of $27.24 \%$. There was a significant difference in percentage of plants with dead growing points among the cowpea genotypes $(F=18.63, P<$ 0.0001) (Table 2). Growing point of the genotypes PI349674 (0), PI293568 (0), and PI293469 (0) were free of damage, suggesting that these genotypes were highly tolerant to growing point death under extreme drought conditions. Significant amount of dead growing points was recorded for the genotypes PI582468 (80\%), PI582812 (87.50\%), PI582573 (89.61\%), PI582665 (91.67\%), PI255774 (91.67\%), PI229734 (93.44\%), and PI666260 (100\%) (Supplemental Table 1). Distributions of dead growing points were bimodal for both fast-wilting and slow-wilting genotypes, and slow-wilting

Table 2. Analysis of variance table for overall plant greenness, stem diameter, dead, lodged, and wilted plants, and plants showing necrotic stems and dead growing points in $28 \mathrm{~d}$ of drought stress, and recovery rate after rewatering plants over 1 week.

\begin{tabular}{|c|c|c|c|c|c|c|}
\hline Traits & Source & DF & Sum of squares & Mean square & $F$ value & Prob $>F$ \\
\hline Plant greenness & Accession & 29 & 30.45 & 1.05 & 7.31 & $<0.0001$ \\
\hline \multirow[t]{2}{*}{ Stem diameter $(\mathrm{mm})$} & Accession & 29 & 7.20 & 0.25 & 3.52 & $<0.0001$ \\
\hline & Residual & 60 & 4.23 & 0.07 & & \\
\hline Dead plants (\%) & Residual & 60 & $4,210.82$ & 70.18 & & \\
\hline \multirow{2}{*}{ Recovery (\%) } & Accession & 29 & $86,051.09$ & $2,967.28$ & 26.32 & $<0.0001$ \\
\hline & Residual & 60 & $6,763.45$ & 112.72 & & \\
\hline \multirow[t]{2}{*}{ Wilted plants (\%) } & Accession & 29 & $6,140.04$ & 211.73 & 20.57 & $<0.0001$ \\
\hline & Residual & 60 & 617.65 & 10.29 & & \\
\hline \multirow[t]{2}{*}{ Necrotic stem (\%) } & Accession & 29 & $67,171.51$ & $2,316.26$ & 15.71 & $<0.0001$ \\
\hline & Residual & 60 & $8,845.14$ & 147.42 & & \\
\hline \multirow[t]{2}{*}{ Dead growing point $(\%)$} & Accession & 29 & $66,772.39$ & $2,302.50$ & 18.63 & $<0.0001$ \\
\hline & Residual & 60 & $7,413.64$ & 123.56 & & \\
\hline
\end{tabular}



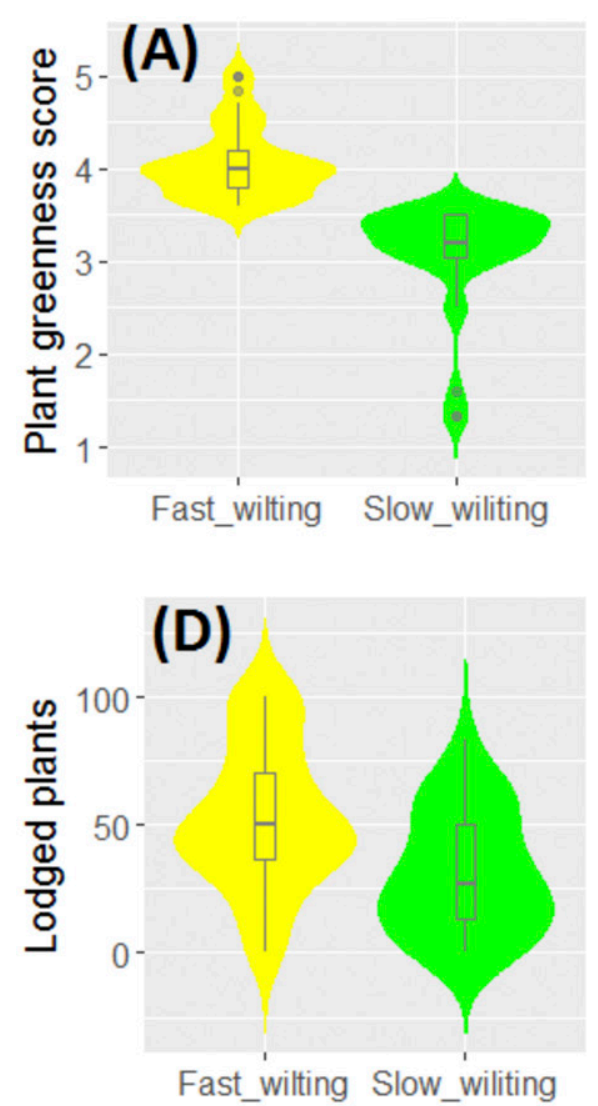
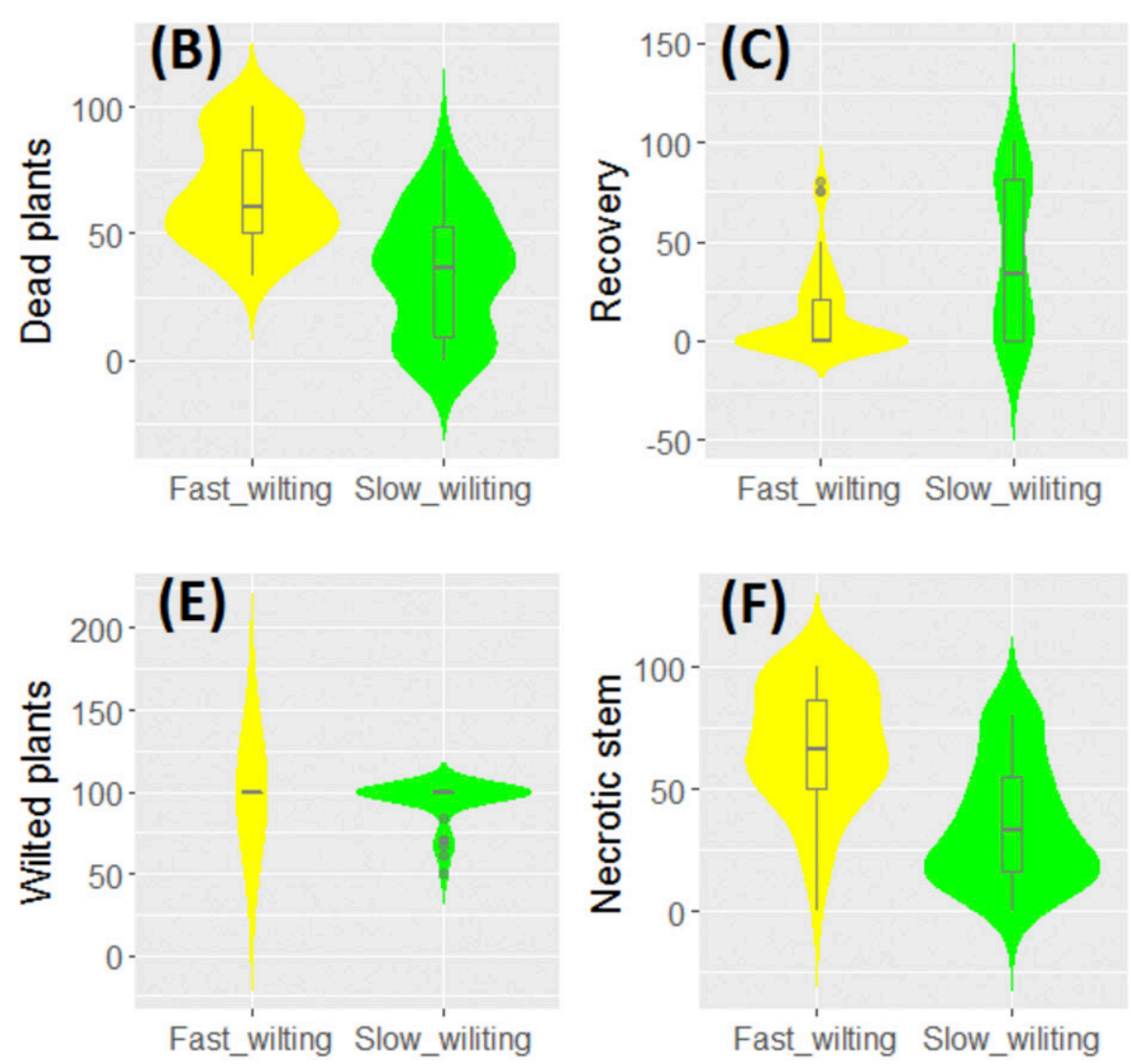

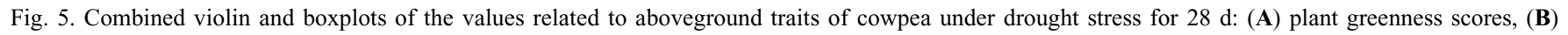
percentage of dead plants, $(\mathbf{C})$ recovery rate after rewatering, (D) percentage of lodged plants, (E) percentage of plants showing wilting sign, and (F) percentage of plants exhibiting necrotic stems.

genotypes had a lower percentage of plants showing dead growing points (Fig. 6B).

Cowpea plants drought-stressed in $28 \mathrm{~d}$ were rewatered. Recovery in plant greenness was noticed in some genotypes, whereas damage caused by drought conditions was not reversible in other genotypes. Number of recovered plants was counted in 1 week after rewatering. Percentage of recovered plants varied from $0 \%$ to $100 \%$, with an average of $30.92 \%$ and an SD of $24.38 \%$. Recovery rate was significantly different among the cowpea genotypes $(F=26.32, P<0.0001)$ (Table 2$)$. The genotypes PI293469, 09-655, PI582402, and PI349674 (Supplemental Table 1) had a good capability of recovering from a prolonged period of extreme drought conditions at seedling stage on rewatering, whereas the genotypes 09-1090, PI180014, PI229734, PI255774, PI339563, PI339610, PI582340, PI582428, PI582468, PI582530, PI582573, PI582665, PI583209, and PI666260 were not capable of recovering. Discrepancy in distributions and recovery rate were identified between fast-wilting and slow-wilting genotypes (Fig. 5C).

\section{Leaf-related parameters under drought stress}

Measurements on unifoliate leaves. Unifoliate leaf length and width were measured before drought stressing the cowpea plants. Results showed that unifoliate leaf length ranged between $6.78 \mathrm{~cm}$ and $11.22 \mathrm{~cm}$, with
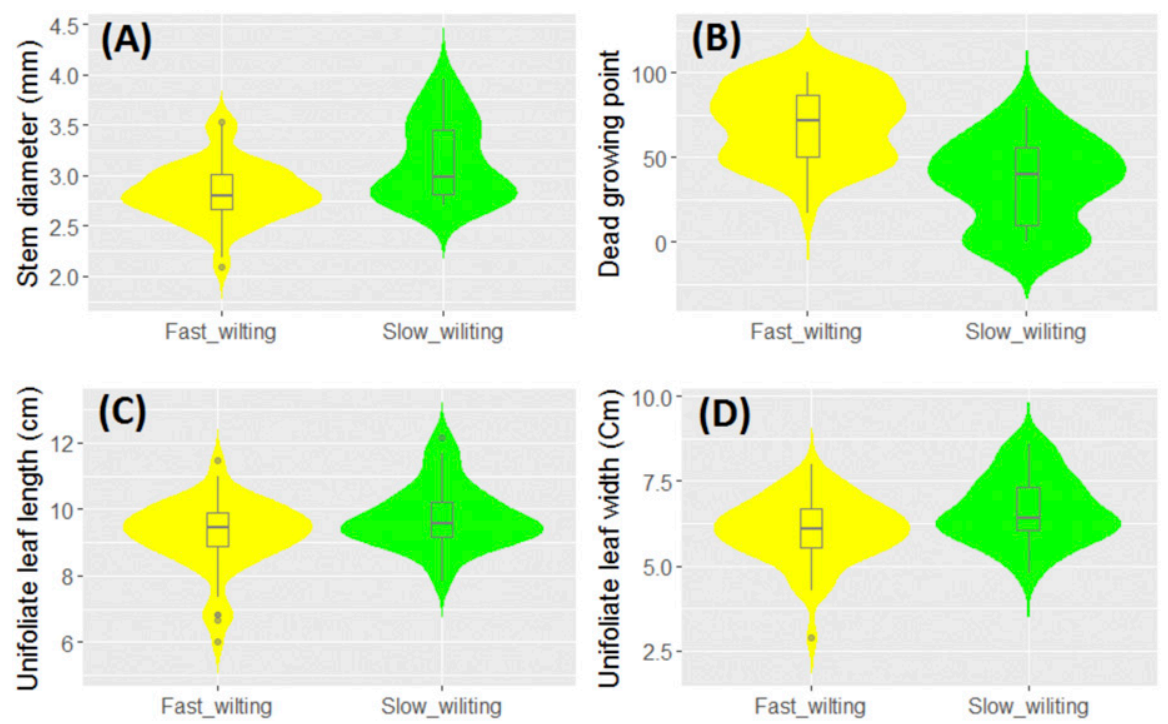

Fig. 6. Combined violin and boxplots for (A) stem diameter $(\mathrm{mm})$ recorded at first sign of wilting, (B) percentage of plants showing dead growing point, (C) unifoliate leaf length, and (D) unifoliate leaf width. Percentage of plants having dead growing points was recorded at $28 \mathrm{~d}$ of drought stress. Stem diameter was measured at first sign of plant wilting. Unifoliate leaf length and width were recorded before imposing drought stress on cowpea plants.

an average of $9.44 \mathrm{~cm}$ and an SD of $0.88 \mathrm{~cm}$ (Supplemental Table 2). Unifoliate leaf length was significantly different among the cowpea genotypes $(F=5.72, P<0.0001)$ (Table 3). The lowest unifoliate leaf length was recorded for PI180014 $(8.81 \mathrm{~cm})$, PI582340 $(8.80 \mathrm{~cm})$, PI582697 $(8.72 \mathrm{~cm})$, PI582512 $(8.70 \mathrm{~cm})$, PI293568 (8.67 cm), PI255774 $(7.28 \mathrm{~cm})$, and PI582812 (6.78 cm); PI582402 (11.22 cm), 09-714 (10.76 cm), 
PI582665 (10.43 cm), PI293469 $(10.22 \mathrm{~cm})$, and PI582368 $(10.18 \mathrm{~cm})$ had the highest unifoliate leaf length.

Unifoliate leaf width was in the range of $4.37 \mathrm{~cm}$ and $8.50 \mathrm{~cm}$, with an average of 6.29 $\mathrm{cm}$ and an SD of $0.87 \mathrm{~cm}$. ANOVA showed significant differences in unifoliate leaf width among the cowpea genotypes $(F=7.30, P<$ 0.0001 ) (Table 3$)$. Genotypes with the largest unifoliate leaves were PI582402 $(8.50 \mathrm{~cm})$, PI293469 (7.85 cm), PI582468 (7.54 cm), 09$1090(7.44 \mathrm{~cm})$, and PI339563 $(7.32 \mathrm{~cm})$. Those with the narrowest unifoliate leaves were PI255774 $(5.17 \mathrm{~cm})$, PI180014 (5.11 $\mathrm{cm})$, and PI582812 (4.37 cm). Both unifoliate leaf length and width were nearly normally distributed and almost similar for fast-wilting and slow-wilting genotypes (Fig. 6C and D).

Tolerance to unifoliate leaf wilting and chlorosis under drought stress. Unifoliate leaf wilting and chlorosis have been frequently used as criteria for drought tolerance evaluation in cowpea seedlings. Data on unifoliate leaf wilting and chlorosis were collected at $28 \mathrm{~d}$ after drought stress. The percentage of plants having wilted unifoliate leaves varied from $22.22 \%$ to $100 \%$, with an average of $77.97 \%$ and an SD of $19.28 \%$ (Supplemental Table 2). Data on unifoliate leaf wilt was skewed to the lower percentage for both fast-wilting and slow-wilting genotypes, with higher percentage of wilting in fast-wilting genotypes (Fig. 7A). Unifoliate leaf wilting was significantly different among the cowpea genotypes $(F=15.19, P<$ 0.0001) (Table 3). Relatively lower percentage of plants showing wilted unifoliate leaves was identified for the genotypes PI349674 (40\%), PI293568 (33.33\%), and PI293469 $(22.22 \%)$, indicating that these genotypes were moderately tolerant to unifoliate leaf wilting under drought stress. However, all plants $(100 \%)$ exhibited wilted unifoliate leaves for the four genotypes PI229734, PI582573, PI582812, and PI666260 (Table 3), suggesting that these genotypes were highly susceptible to unifoliate leaf wilting when drought-stressed.

A large variation in tolerance to unifoliate leaf chlorosis was identified among the cowpea genotypes evaluated for drought tolerance. The percentage of plants showing chlorotic unifoliate leaves ranged between $5.56 \%$ and $100 \%$, with an average of $75.48 \%$ and an SD of $26.22 \%$. Unifoliate leaf chlorosis was skewed to a lower percentage for the fast-wilting genotypes, whereas it was bimodal for the slow-wilting genotypes with a lower percentage compared with the fast-wilting genotypes (Fig. 7B). Significant differences in unifoliate leaf chlorosis were identified $(F=16.14, P<0.0001)$ (Table 3). The lowest percentage of plants with chlorotic unifoliate leaves was recorded for the genotypes PI293568 (22.22\%), PI349674 (14.39\%), and PI293469 (5.56\%) (Supplemental Table 2), indicating that these genotypes were tolerant to unifoliate leaf chlorosis under drought stress. The genotypes highly susceptible $(100 \%)$ to unifoliate leaf chlorosis were PI180014, PI229734, PI255774, PI582368, PI582530, PI582551, PI582573, and PI582812 (Supplemental Table 3).

Table 3. Analysis of variance table for unifoliate leaf length and width measured on the last day of watering, percentage of plants showing wilted, chlorotic, and necrotic unifoliate and trifoliate leaves $21 \mathrm{~d}$ after drought stress.

\begin{tabular}{llrrrrr}
\hline Traits & Source & DF & Sum of squares & Mean square & $F$ value & Prob $>F$ \\
\hline Unifoliate leaf length & Accession & 29 & 70.45 & 2.43 & 5.72 & $<0.0001$ \\
& Residual & 60 & 25.48 & 0.42 & & \\
Unifoliate leaf width & Accession & 29 & 68.26 & 2.35 & 7.30 & $<0.0001$ \\
& Residual & 60 & 19.34 & 0.32 & & $<0.0001$ \\
Unifoliate leaf wilt & Accession & 29 & $33,458.30$ & $1,153.73$ & 15.19 & \\
& Residual & 60 & $13,328.96$ & 222.15 & & $<0.0001$ \\
Unifoliate leaf chlorosis & Accession & 29 & $61,873.74$ & $2,133.58$ & 16.14 & \\
Trifoliate leaf wilt & Residual & 60 & $7,932.64$ & 132.21 & & $<0.0001$ \\
& Accession & 29 & $17,385.45$ & 599.50 & 11.02 & \\
Trifoliate leaf chlorosis & Residual & 60 & $5,215.63$ & 86.93 & & $<0.0001$ \\
& Accession & 29 & $9,872.01$ & 340.41 & 12.42 & 27.41 \\
\hline
\end{tabular}
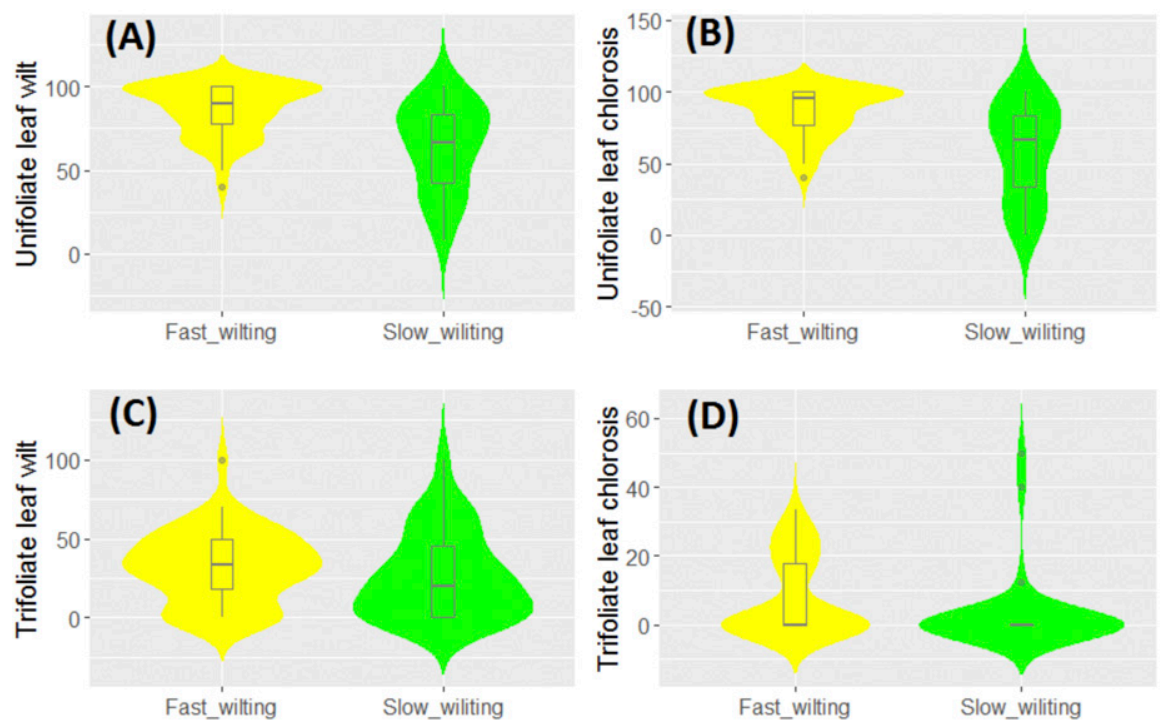

Fig. 7. Percentage of plants showing signs of (A) wilting on unifoliate leaves, (B) chlorosis on unifoliate leaves, (C) wilting on trifoliate leaves, and (D) chlorosis on trifoliate leaf. Data were recorded at $28 \mathrm{~d}$ of drought stress.

Tolerance to trifoliate leaf wilting and chlorosis under drought stress. The percentage of plants with wilted trifoliate leaf at $28 \mathrm{~d}$ after drought stress varied from $0 \%$ to $60.28 \%$, with an average of $29.75 \%$ and an SD of $13.90 \%$. Distribution of trifoliate leaf wilt was bimodal for the fast-wilting genotypes, whereas it was skewed to higher percentage for the slow-wilting genotypes (Fig. 7C). The percentage of plants presenting chlorotic trifoliate leaves varied from $0 \%$ to $31.67 \%$, with an average of $10.47 \%$ and an SD of $6.09 \%$. These results suggested that cowpea plants were more tolerant to trifoliate leaf chlorosis than trifoliate leaf wilting. Significant differences in both trifoliate leaf wilting $(F=11.02, P<0.0001)$ and trifoliate leaf chlorosis $(F=12.42, P<0.0001)$ were identified among the cowpea genotypes. The genotypes PI582551 (11.11\%), PI349674 (9.17\%), and PI293469 (0) were tolerant to trifoliate leaf wilting when drought-stressed, whereas the genotypes PI229734, PI255774, PI582468, and PI582573 were severely affected by trifoliate leaf wilting under drought conditions (Supplemental Table 2). Most of the genotypes evaluated for drought tolerance were tolerant trifoliate leaf chlorosis except for 09-714 (31.67\%), PI229734 (25.94\%), PI255774 (25.00\%), PI582573 (24.81\%), PI582368 (24.45\%), PI582512 (20.89\%), PI583209 (16.17\%), and PI582812 (13.89\%).

\section{Chlorophyll contents under drought stress}

Covariance matrix identification for repeated measure analysis. Estimates of -2 Res Log Likelihood, AICC, Bias-corrected Small Sample AICC, and Bayesian Information Criterion were calculated for a total of eight types of covariance matrix (Unstructured, independence with equal variance, first order autoregressive, Toeplitz, Toeplitz with two bands, Toeplitz with three bands, heterogeneous independence, and heterogeneous first order autoregressive). For the traits involving chlorophyll (SPAD values) in unifoliate leaves, chlorophyll (SPAD values) in trifoliate leaves, and ratio between chlorophyll content in trifoliate and unifoliate leaves, the lowest estimates were found using an unstructured covariance matrix type except for Bayesian Information Criterion for trifoliate leaf chlorophyll (Supplemental Table 4). 
Therefore, ANOVA involving time series analysis for chlorophyll contents was conducted based on an unstructured covariance matrix type.

Time by genotype effect on chlorophyll content under drought stress. Extensive leaf damage was identified at $28 \mathrm{~d}$ after drought stress, which made chlorophyll measurement difficult at that time. Therefore, data on chlorophyll content was collected at $7 \mathrm{~d}, 14 \mathrm{~d}$, and $21 \mathrm{~d}$ after drought stress, respectively. Unifoliate leaf and trifoliate leaf chlorophyll was near normally distributed (Fig. 8A and B). ANOVA with repeated measure analysis revealed significant genotype-by-time effects on the mean response of unifoliate leaf chlorophyll $(F=5.69, P<0.0001)$, trifoliate leaf chlorophyll $(F=4.40, P<0.0001)$, and ratio between chlorophyll content in unifoliate leaves and trifoliate leaves $(F=9.81, P<$ 0.0001 ) (Table 4). Overall, chlorophyll in unifoliate leaves decayed over time, with the lowest average recorded at $21 \mathrm{~d}$ after drought stress (Fig. 8A), whereas that of trifoliate leaves slightly increased at $14 \mathrm{~d}$ after drought stress, and decreased at $21 \mathrm{~d}$ after drought stress, as shown in Fig. 8B.

The ratio between chlorophyll content in trifoliate leaves and unifoliate leaves was calculated and used as an indicator to assess the discrepancy in chlorophyll content between the different leaf types of drought-stressed cowpea plants at the seedling stage. Results indicated a ratio close to 1 at $7 \mathrm{~d}$ after drought stress, suggesting that nutrients were likely evenly distributed within the plant shoot. The ratio increased with a value that gradually deviated from 1 (Fig. 8C), indicating a mobilization of nutrients to the upper part of the plants when soil moisture became more and more insufficient.

A more detailed view of the average chlorophyll in unifoliate and trifoliate leaves on a per genotype basis was shown using a heatmap (Fig. 9). Overall, the cowpea genotypes were clustered into three groups based on the average chlorophyll over the period of drought stress (Fig. 9). Cluster 1 (middle section of the heatmap) consisted of genotypes with an overall increase in chlorophyll at $14 \mathrm{~d}$ after drought stress and a less severe decrease in chlorophyll content at $21 \mathrm{~d}$ after drought stress. PI349674, PI293469, and PI293568 had the highest average chlorophyll content at $21 \mathrm{~d}$ after drought stress, suggesting that these genotypes were drought tolerant. Cluster 2 (upper section of the heatmap) included genotypes with a decrease in average chlorophyll content over time, whereas cluster 3 (lower section of the heatmap) involved genotypes with a rapid decrease in average chlorophyll content, resulting in plant death for some of the genotypes at $21 \mathrm{~d}$ after drought stress.

Correlation between traits and network analysis. Establishing a relationship between different drought tolerance-related traits would provide cowpea breeders with more powerful information when selecting genotypes for further crop improvement. Correlation between the responses of the aboveground plant parts under drought stress was analyzed
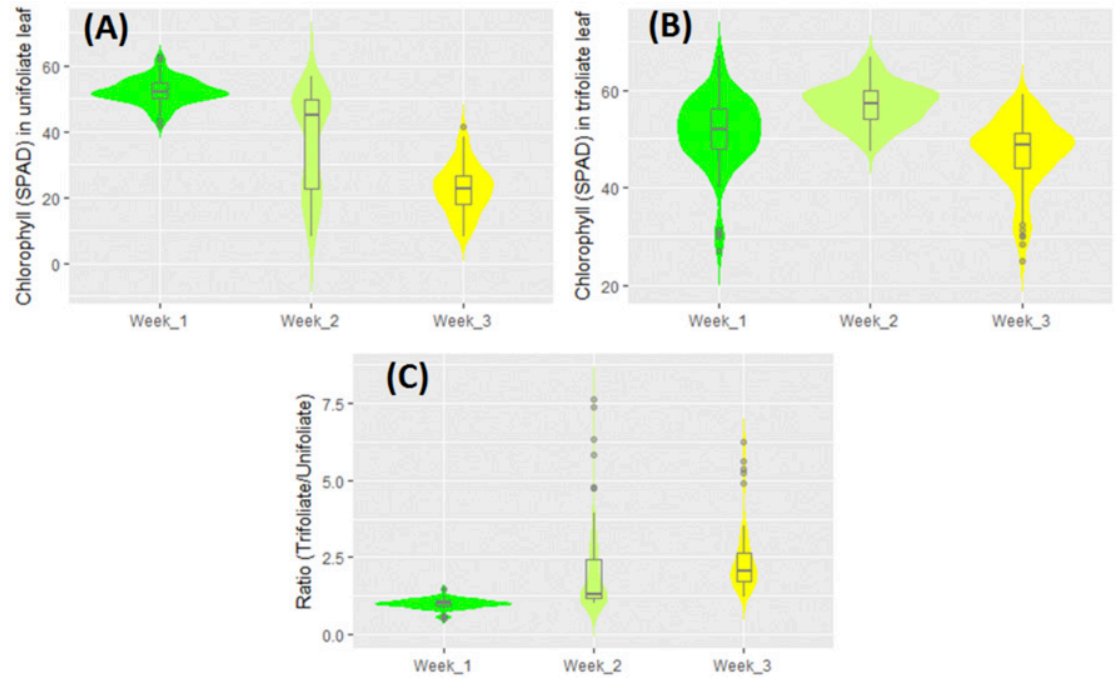

Fig. 8. Chlorophyll (SPAD values) in (A) unifoliate leaves and (B) trifoliate leaves over time. Ratio (C) between chlorophyll in unifoliate leaves and trifoliate leaves, respectively. Week 1 , week 2 , and week 3 corresponded to $7 \mathrm{~d}, 14 \mathrm{~d}$, and $21 \mathrm{~d}$ of drought stress.

Table 4. Analysis of variance (type 3 tests of fixed effects) involving time series analysis under unstructured covariance matrix model for chlorophyll (SPAD) contents in unifoliate leaves, trifoliate leaves, and ratio between chlorophyll content (SPAD) in unifoliate leaves and trifoliate leaves.

\begin{tabular}{llccrc}
\hline Parameters & \multicolumn{1}{c}{ Effect } & Num DF & Den DF & $F$ value & $\operatorname{Pr}>F$ \\
\hline Chlorophyll content in unifoliate leaves & Accessions & 29 & 60 & 4.37 & $<0.0001$ \\
& Time & 2 & 60 & 2679.47 & $<0.0001$ \\
& Accessions*Time & 58 & 60 & 5.69 & $<0.0001$ \\
Chlorophyll content in trifoliate leaves & Accessions & 29 & 60 & 3.97 & $<0.0001$ \\
& Time & 2 & 60 & 251.02 & $<0.0001$ \\
& Accessions*Time & 58 & 60 & 4.4 & $<0.0001$ \\
Ratio of chlorophyll content between & Accessions & 29 & 60 & 6.23 & $<0.0001$ \\
trifoliate and unifoliate leaves & Time & 2 & 60 & 650.25 & $<0.0001$ \\
& Accessions*Time & 58 & 60 & 9.81 & $<0.0001$ \\
\hline
\end{tabular}

to generate a possible phenotypic pathway that can help better understand the drought tolerance mechanism in the cowpea. To date, little has been reported regarding generating a phenotypic network between drought tolerance-related traits in cowpea. High correlation coefficients $(|r|>0.65)$ (Supplemental Table 5) were found between percentage of dead plants and recovery rate $(r=-0.70)$, percentage of dead plants and lodged plants $(r=0.73)$, percentage of dead plants and those showing necrotic stems $(r=0.69)$, percentage of dead plants and those with dead growing points $(r=$ $0.87)$, percentage of dead plants and plant greenness score $(r=0.73)$, and percentage of dead plants and tolerance to unifoliate leaf chlorosis $(r=0.71)$. In addition, results revealed high correlations between unifoliate leaf chlorosis and unifoliate leaf wilt under drought stress $(r=0.73)$ and unifoliate leaf chlorosis and chlorophyll content $(r=-0.72)$. A network between these highly correlated traits, percentage of dead plants, lodged plants, recovery rate, necrotic stems, dead growing points, plant greenness, and leaf chlorophyll content, was established and is shown in Fig. 10. Interestingly, low correlations were found between unifoliate leaf length/width and tolerance to drought in cowpea seedlings (Fig. 10). Low correlations were found between stem diameter and tolerance to drought toler- ance. Plant death under drought conditions was lowly correlated with both trifoliate leaf wilt and chlorosis.

Network analysis between the different traits evaluated under water deficit conditions showed two clear clusters (Fig. 10). The first consisted of highly correlated traits, such as recovery rate, percentage of lodged plants, dead plants, dead growing points, stem necrosis, plant greenness, unifoliate leaf wilting chlorosis, unifoliate leaf wilting, unifoliate leaf chlorophyll, and chlorophyll ratio between trifoliate and unifoliate leaves. The second group was defined as a set of disjointed clusters of traits that mainly consisted of phenotypes related to plant architecture, such as stem diameter and leaf width/length. These findings suggested that drought tolerance-related phenotypes investigated could be potentially linked to genetics rather than adaptation of plants to water deficient conditions due to plant architecture.

\section{Discussion}

Drought has been shown to be an increasing threat to crop production worldwide (Cairns et al., 2013; Upadhyaya, 2005; Upadhyaya et al., 2017). Being provided with crops that are more resilient to drought conditions is an affordable strategy to cope with the effects of drought stress. Therefore, 

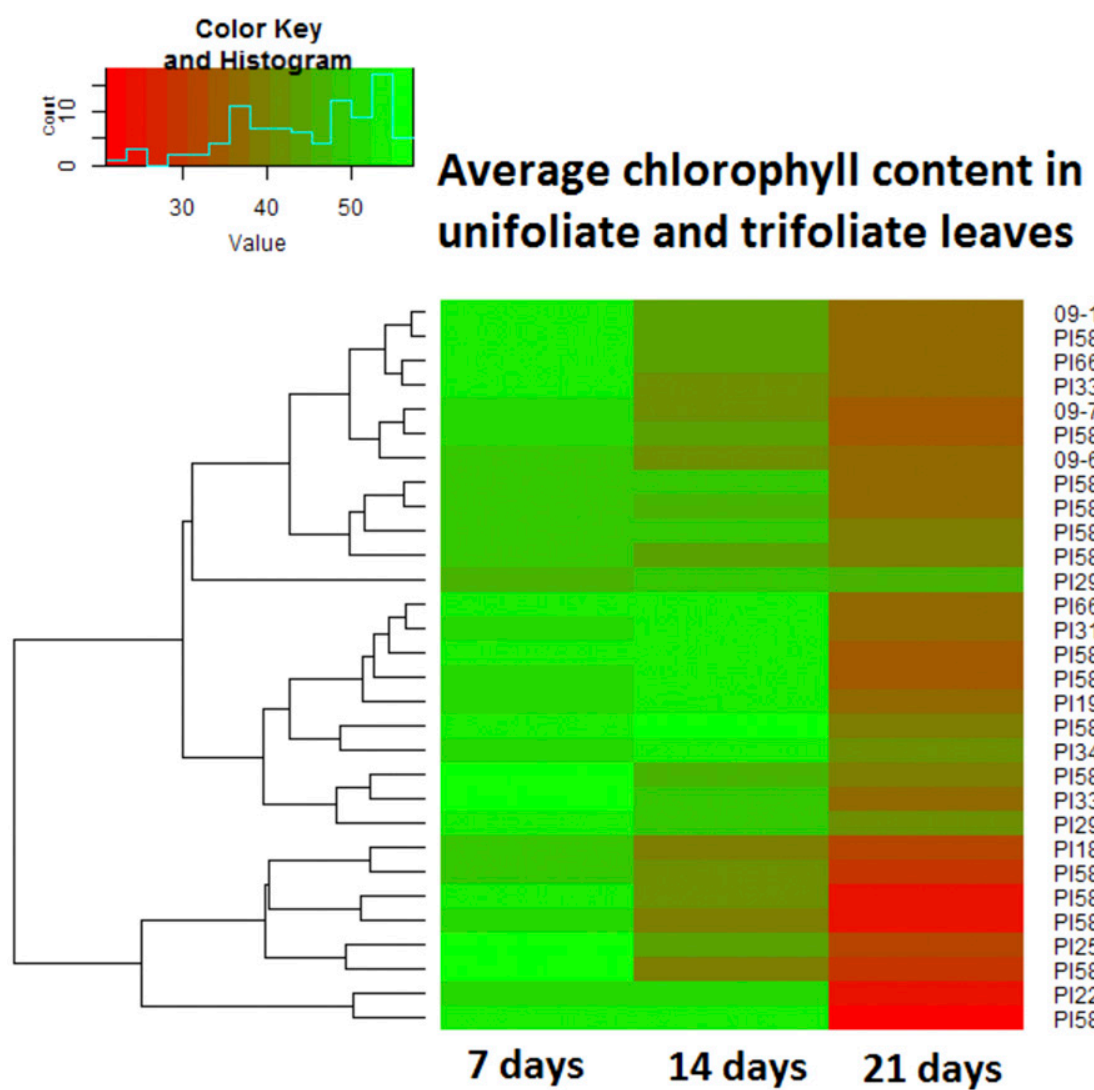

Fig. 9. Heatmap of the average chlorophyll content (SPAD) in unifoliate and trifoliate leaves at $7 \mathrm{~d}, 14 \mathrm{~d}$, and $21 \mathrm{~d}$ of drought stress, respectively. Green indicated high chlorophyll content, whereas red indicated low chlorophyll content.
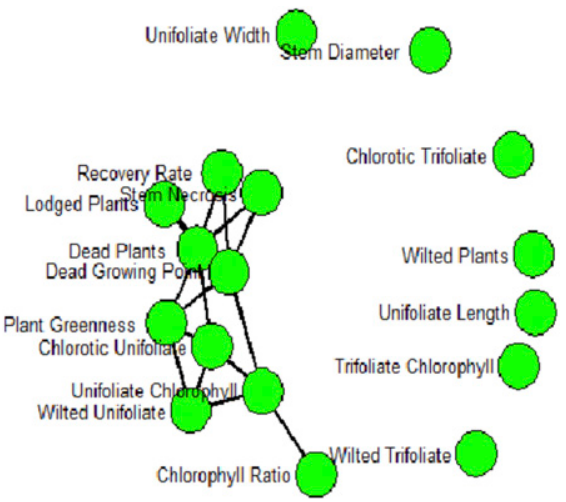

Fig. 10. Network analysis between traits evaluated under drought stress in cowpea. Path was shown using solid lines if Person's coefficient value between trait values was greater than 0.65 .

breeding for drought-tolerant crops could alleviate the effects of drought tolerance in agriculture. Drought occurring at early vegetative development has been demonstrated to be extremely damaging to cowpea production (Agbicodo et al., 2009). However, less progress has been made toward breeding and releasing drought-tolerant cowpea cultivars that would better withstand drought stress at the early season. The need for a robust, fast, and cost-effective phenotyping strategy would significantly assist cowpea breeders in advancing their programs for drought tolerance. Information on cowpea drought tolerance at the seedling stage would be substantial in efforts toward developing drought-tolerant cultivars. Tomar et al. (2016) showed that plants with good tolerance at early vegetative growth were able to withstand drought stress at a later stage of plant development. Another study demonstrated that plant genotypes with some degree of drought tolerance at the seedling stage were likely to be drought tolerant at later stages (Rzepka-Plevneš et al., 2009). With the recent advances in modern plant breeding, the performance of progenies could be accurately predicted using genomic selection tools (Hayes et al., 2009). This relatively recently developed tool also can be applied to improve germplasm tolerance to drought and the availability of detailed phenotypic data on drought tolerance is critical to do so.

In this report, a large variation in different traits evaluated for drought was found among the cowpea genotypes. A total of 17 aboveground traits were evaluated under drought stress. Network analysis between these traits was established and indicated that failure to tolerate unifoliate leaf wiling/chlorosis and stem necrosis and to maintain plant greenness phenomenon led to significant plant death in cowpea genotypes, which resulted in a low recovery rate when water supplies were reestablished. Highly correlated clusters of traits were found for the drought-stressed cowpea plants (Fig. 10). These correlated variables provided information on a possible genetic network associated with drought tolerance in cowpea. Further investigations are required to identify the major element of the network that can significantly regulate all the other components of the network.

Overall, most of the genotypes were more tolerant to trifoliate leaf wilting/chlorosis than unifoliate leaf wilting/chlorosis, which was in agreement with the results provided by Verbree et al. (2015). The mechanism of drought tolerance occurring at leaf level during the seedling stage is an important criterion in determining drought tolerance type in the cowpea. Mai-Kodomi et al. (1999) described two types of drought tolerance in cowpea. Type I drought-tolerant cowpea has the ability to delay senescence in both trifoliate and unifoliate leaves, whereas type II is more tolerant to trifoliate wilt/chlorosis but more susceptible to unifoliate wilt/chlorosis. Our results suggested that most of genotypes were type II drought tolerant. The genotype PI293469 (Figs. 3 and 9) was considered type I drought tolerant.

Delayed senescence phenomenon was assessed by evaluating plant greenness and taking measurement on chlorophyll (SPAD data) in both trifoliate and unifoliate leaves in drought-stressed cowpea. Our results indicated an overall increase in chlorophyll content in trifoliate leaf at $14 \mathrm{~d}$ after drought stress. This could be explained by a transport of nutrients to the upper shoot part at $14 \mathrm{~d}$ after drought stress. Our data indicated that PI293469, PI349674, and PI293568 proved to successfully maintain this mechanism even at $21 \mathrm{~d}$ after drought stress. An attempt to unravel the mechanisms of drought tolerance in legumes such as chickpea (Cicer arietinum L.) was conducted by $\mathrm{Li}$ et al. (2018). Candidate genes such as auxin efflux carrier protein (PIN3), p-glycoprotein, and nodulin MtN21/EamA-like transporter were identified to probably confer drought tolerance in chickpea. Auxin efflux carrier protein (PIN3) was reported to enhance cell-to-cell auxin transport, which is critical in maintaining plant growth (Zourelidou et al., 2014). In Arabidopsis, Remy et al. (2013) showed that these auxin transporters were further enhanced by a superfamily of transporters regulating potassium and proton movement between plant cells. In maize (Zea mays L.), Yue et al. (2015) reported high expression of auxin transporter-related genes under drought stress. With an enhanced auxin transport, droughttolerant crops had better ability of mobilizing nutrients to younger plant tissues for surviving (Remy et al., 2013; Yue et al., 2015), which could explain the increase in chlorophyll content in trifoliate leaves of cowpea plants at $14 \mathrm{~d}$ after drought stress, as reported in this current investigation. However, further research is required to provide scientific evidence of the genetics of drought tolerance in cowpea.

Research aiming at identifying the most suitable plant morphology and root architecture for enhancing drought tolerance has been extensively investigated in cowpea (Ajayi et al., 2018; Burridge et al.; 2017). In this study, the effects of plant architecture on enhancing drought tolerance were limited by growing cowpea within sterility polypropylene boxes, which explained the absence of path 
analysis between leaf size and drought tolerance. The type I drought-tolerant cowpea, PI293469, had the largest stem dimeter $(P<0.0001)$ at first sign of wilting despite limiting adaptation of cowpea due to plant morphology. This suggested that this genotype could have the ability to better store carbohydrate in stems under drought conditions, which could contribute to its tolerance to drought conditions. Similar results were reported by Singh et al. (1999) and Verbree et al. (2015) claiming tolerance to drought was recognized as moderately to stem diameter in cowpea seedlings. This current investigation will help scientists better understand drought tolerance and provides information on drought-related traits for selecting cowpea lines with good tolerance to water deficient conditions.

\section{Literature Cited}

Agbicodo, E.M., C.A. Fatokun, S. Muranaka, R.G.F. Visser, and C.G. van der Linden. 2009. Breeding drought tolerant cowpea: Constraints, accomplishments, and future prospects. Euphytica 167(3):353-370

Ajayi, A.T., A.E. Gbadamosi, and V.O. Olumekun. 2018. Screening for drought tolerance in cowpea (Vigna unguiculata L. Walp) at seedling stage under screen house condition. Intl. J. Biotechnol. 11(1):1-9.

Blum, A. and A. Ebercon. 1981. Cell membrane stability as a measure of drought and heat tolerance in wheat. Crop Sci. 21(1):43-47.

Burridge, J.D., H.M. Schneider, B.L. Huynh, P.A Roberts, A. Bucksch, and J.P. Lynch. 2017. Genome-wide association mapping and agronomic impact of cowpea root architecture. Theor. Appl. Genet. 130(2):419-431.

Cairns, J.E., J. Crossa, P.H. Zaidi, P. Grudloyma, C. Sanchez, J.L. Araus, S. Thaitad, D. Makumbi, C. Magorokosho, M. Bänziger, and A. Menkir. 2013. Identification of drought, heat, and combined drought and heat tolerant donors in maize. Crop Sci. 53(4):1335-1346.

Carvalho, M., T. Lino-Neto, E. Rosa, and V. Carnide. 2017. Cowpea: A legume crop for a challenging environment. J. Sci. Food Agr. 97:4273-4284.

Dhanapal, A.P., J.D. Ray, S.K. Singh, V. HoyosVillegas, J.R. Smith, L.C. Purcell, C. Andy King, P.B. Cregan, Q. Song, and F.B. Fritschi. 2015. Genome-wide association study (GWAS) of carbon isotope ratio $(\delta 13 \mathrm{C})$ in diverse soybean [Glycine max (L.) Merr.] genotypes. Theor. Appl. Genet. 128(1):73-91.

Escalante, C., M. Song, and C. Dodson. 2016. FSA farm loan repayment under economic recession and drought conditions. Agr. Financ. Rev. 76(4):445-461.
Fatokun, C.A., O. Boukar, and S. Muranaka. 2012. Evaluation of cowpea (Vigna unguiculata (L.) Walp.) germplasm lines for tolerance to drought. Plant Genet. Resour. 10(3):171-176.

Frota, K.D.M.G., R.A.M. Soares, and J.A.G. Arêas. 2008. Chemical composition of cowpea (Vigna unguiculata L. Walp), BRS-Milênio cultivar. Food Sci. Technol. 28(2):470-476.

Golldack, D., C. Li, H. Mohan, and N. Probst. 2014. Tolerance to drought and salt stress in plants: Unraveling the signaling networks. Front. Plant Sci. 5:151.

Hayes, B.J., P.J. Bowman, A.C. Chamberlain, K. Verbyla, and M.E. Goddard. 2009. Accuracy of genomic breeding values in multi-breed dairy cattle populations. Genet. Sel. Evol. 41(1):51.

Ishiyaku, M.F. and H. Aliyu. 2013. Field evaluation of cowpea genotypes for drought tolerance and striga resistance in the dry savanna of the North-West Nigeria. Intl. J. Plant Breeding Genet. 7:47-56.

Li, Y., P. Ruperao, J. Batley, D. Edwards, T. Khan, T.D. Colmer, J. Pang, K.H.M. Siddique, and T. Sutton. 2018. Investigating drought tolerance in chickpea using genome-wide association mapping and genomic selection based on whole-genome resequencing data. Front. Plant Sci. 9:190

Littell, R.C., J. Pendergast, and R. Natarajan. 2000 Tutorial in biostatistics: Modelling covariance structure in the analysis of repeated measures data. Stat. Med. 19(13):1793-1819.

Mai-Kodomi, Y., B.B. Singh, and O. Myers. 1999. Two mechanisms of drought tolerance in cowpea. Indian J. Genet. Plant Breed. 59(3):309-316.

Moreira-Araújo, R.S.D.R., G.R. Sampaio, R.A.M. Soares, C.P. Silva, and J.A.G. Arêas. 2017. Identification and quantification of antioxidant compounds in cowpea. Rev. Cienc. Agron. 48(5):799-805.

Muchero, W., J.D. Ehlers, T.J. Close, and P.A Roberts. 2009. Mapping QTL for drought stress-induced premature senescence and maturity in cowpea [Vigna unguiculata (L.) Walp.]. Theor. Appl. Genet. 118(5):849-863.

Okiror, S.O., J.C. Onyilagha, and T. Dunbar. 2008. Investigating the potentials of four cowpea (southern pea) cultivars for fresh seed production. Intl. J. Appl. Agr. Res. 3(1):67-74.

Remy, E., T.R. Cabrito, P. Baster, R.A. Batista, M.C. Teixeira, J. Friml, I. Sá-Correia, and P. Duque. 2013. A major facilitator superfamily transporter plays a dual role in polar auxin transport and drought stress tolerance in $\mathrm{Arab}$ idopsis. Plant Cell 25(3):901-926.

Rosine, J. and N.W. Bull. 1989. Drought, agriculture, and the economy. Fed. Reserve Bull. 75(1):1.

Rzepka-Plevneš, D., M. Krupa-Małkiewicz, J. Kurek, and M. Smolik. 2009. Effects of water deficits on development and yield of rye varieties differing in tolerance to drought at seedling stage. J. Food Agr. Environ. 7:492-495.

Singh, B.B., H.A. Ajeigbe, S.A. Tarawali, S. Fernandez-Rivera, and M. Abubakar. 2003. Improving the production and utilization of cowpea as food and fodder. Field Crops Res. 84(1):169-177.

Singh, B.B., Y. Mai-Kodomi, and T. Terao. 1999. A simple screening method for drought tolerance in cowpea. Indian J. Genet. Plant Breed. 59(2):211-220.

Specht, J.E., K. Chase, M. Macrander, G.L. Graef, J. Chung, J.P. Markwell, M. Germann, J.H. Orf, and K.G. Lark. 2001. Soybean response to water. Crop Sci. 4(2):493-509.

Tomar, R.S., S. Tiwari, B.K. Naik, S. Chand, R. Deshmukh, N. Mallick, S. Singh, N.K. Singh, and S.M. Tomar. 2016. Molecular and morphoagronomical characterization of root architecture at seedling and reproductive stages for drought tolerance in wheat. PLoS One 11(6): e0156528.

Upadhyaya, H.D. 2005. Variability for drought resistance related traits in the mini core collection of peanut. Crop Sci. 45(4):1432-1440.

Upadhyaya, H.D., S.L. Dwivedi, M. Vetriventhan, L. Krishnamurthy, and S.K. Singh. 2017. Postflowering drought tolerance using managed stress trials, adjustment to flowering, and mini core collection in sorghum. Crop Sci. 57(1): 310-321.

Verbree, D.A., B.B. Singh, and W.A. Payne. 2015. Genetics and heritability of shoot drought tolerance in cowpea seedlings. Crop Sci. 55(1): 146-153.

Weng, Y., A. Shi, W.S. Ravelombola, W. Yang, J. Qin, D. Motes, D.O. Moseley, and P. Chen. 2017. A rapid method for measuring seed protein content in cowpea (Vigna unguiculata (L.) Walp)). Amer. J. Plant Sci. 8(10):2387-2396.

Wu, H. and D.A. Wilhite. 2004. An operational agricultural drought risk assessment model for Nebraska, USA. Nat. Hazards 33(1):121.

Yue, R., S. Tie, T. Sun, L. Zhang, Y. Yang, J. Qi, S. Yan, X. Han, H. Wang, and C. Shen. 2015. Genome-wide identification and expression profiling analysis of ZmPIN, ZmPILS, ZmLAX and $Z m A B C B$ auxin transporter gene families in maize (Zea mays L.) under various abiotic stresses. PLoS One 10(3):e0118751.

Zourelidou, M., B. Absmanner, B. Weller, I.C.R. Barbosa, B.C. Willige, A. Fastner, V. Streit, S.A. Port, J. Colcombet, S.D.V. Bentem, and H. Hirt. 2014. Auxin efflux by PIN-FORMED proteins is activated by two different protein kinases, D6 PROTEIN KINASE and PINOID. eLife 3:e02860. 